\title{
Association Between Body Mass Index and Mortality in Patients Requiring Cardiac Critical Care
}

\author{
Soo Jin Na, MD; Taek Kyu Park, MD; Joo Myung Lee, MD; Young Bin Song, MD; \\ Jin-Oh Choi, MD; Joo-Yong Hahn, MD; Jin-Ho Choi, MD; Seung-Hyuk Choi, MD; \\ Hyeon-Cheol Gwon, MD; Chi Ryang Chung, MD; Kyeongman Jeon, MD; Gee Young Suh, MD; \\ Joong Hyun Ahn; Keumhee C Carriere, PhD; Jeong Hoon Yang, MD
}

\begin{abstract}
Background: Data on the association between obesity and mortality in patients who require acute cardiac care are limited, so we investigated the effect of obesity on clinical outcomes in patients admitted to the cardiac intensive care unit (CICU).

Methods and Results: We reviewed 2,429 eligible patients admitted to the CICU at Samsung Medical Center between January 2012 and December 2015. After excluding 197 patients with low body mass index (BMI) to adjust for the possibility of frailty, patients were divided into 3 categories: normal BMI ( $n=822), 18.5-22.9 \mathrm{~kg} / \mathrm{m}^{2} ;$ moderate BMI $(n=1,050), 23-27.4 \mathrm{~kg} / \mathrm{m}^{2}$; and high BMI $(n=360)$, $\geq 27.5 \mathrm{~kg} / \mathrm{m}^{2}$. The primary outcome was 28 -day mortality. Overall, $124(2.6 \%)$ of 2,232 patients died during 28-day follow-up after $\mathrm{CICU}$ admission. The 28 -day mortality was numerically lower in the moderate (4.5\%) and high (5.3\%) BMI groups than in the normal BMl group $(7.1 \%)$, but the difference was not statistically significant $(\mathrm{P}=0.052)$. After multivariable adjustment, the moderate and high $\mathrm{BMI}$ categories were not significant predictors of primary outcome (adjusted hazard ratio [HR] $0.74,95 \% \mathrm{Cl} 0.50-1.09, \mathrm{P}=0.127$ and adjusted HR 0.80, 95\% Cl 0.47-1.36, P=0.404, respectively). However, Acute Physiology and Chronic Health Evaluation II scores, liver cirrhosis, malignancy, history of cardiac arrest, and need for organ support treatment were independent predictors of 28-day mortality.
\end{abstract}

Conclusions: Obesity was not associated with short-term mortality in patients requiring cardiac critical care.

Key Words: Cardiac critical care; Death; Obesity

$\mathbf{O}$ besity is a well-known major risk factor and is related to several comorbid conditions that predispose to cardiovascular disease, the number one cause of death globally. ${ }^{1,2}$ In the general population, obesity is associated with increased risk of death from all causes and cardiovascular disease regardless of sex or age. ${ }^{3}$ Although still controversial, some studies conducted in critically ill patients with conditions such as septic shock and acute respiratory distress syndrome have reported reduced mortality in overweight and/or obese patients, which is known as the 'obesity paradox'.,5 One possibility for inconsistent results regarding the obesity-mortality relationship may be that disease severity status is not properly controlled, particularly in intensive care unit (ICU) patients. In the field of cardiac critical care, previous studies of the clinical impact of obesity have focused on acute myocardial infarction and acute heart failure. 6,7 To date, limited data on the association between obesity and mortality in the overall patients who require acute cardiac critical care are available. Therefore, we investigated the association of body mass index (BMI) with clinical outcomes in patients admitted to a cardiac ICU (CICU).

\section{Study Population}

We retrospectively reviewed 2,929 consecutive patients admitted to the CICU at Samsung Medical Center, a tertiary-care center in Seoul, Korea, between January 2012 and December 2015. Patients who had no diagnosis of cardiovascular disease and no available BMI were excluded. The 2,429 eligible patients were classified into 4 categories

Received July 31, 2018; revised manuscript received December 26, 2018; accepted January 9, 2019; J-STAGE Advance Publication released online February 16, 2019 Time for primary review: 21 days

Department of Critical Care Medicine (S.J.N., C.R.C., K.J., G.Y.S., J.H.Y.), Division of Cardiology, Department of Medicine, Heart Vascular Stroke Institute (T.K.P., J.M.L., Y.B.S., J.O.C., J.Y.H., J.H.C., S.H.C., H.C.G., J.H.Y.), Division of Pulmonary and Critical Care Medicine, Department of Medicine (K.J., G.Y.S.), Biostatistics and Clinical Epidemiology Center (J.H.A., K.C.C.), Samsung Medical Center, Sungkyunkwan University School of Medicine, Seoul, Republic of Korea; Department of Mathematical and Statistical Sciences, University of Alberta, Edmonton, Alberta (K.C.C), Canada

Mailing address: Jeong Hoon Yang, MD, PhD, Department of Critical Care Medicine and Division of Cardiology, Department of Medicine, Samsung Medical Center, Sungkyunkwan University School of Medicine, 81 Irwon-ro, Gangnam-gu, Seoul 06351, Republic of Korea. E-mail: jhysmc@gmail.com

ISSN-1346-9843 All rights are reserved to the Japanese Circulation Society. For permissions, please e-mail: cj@j-circ.or.jp 


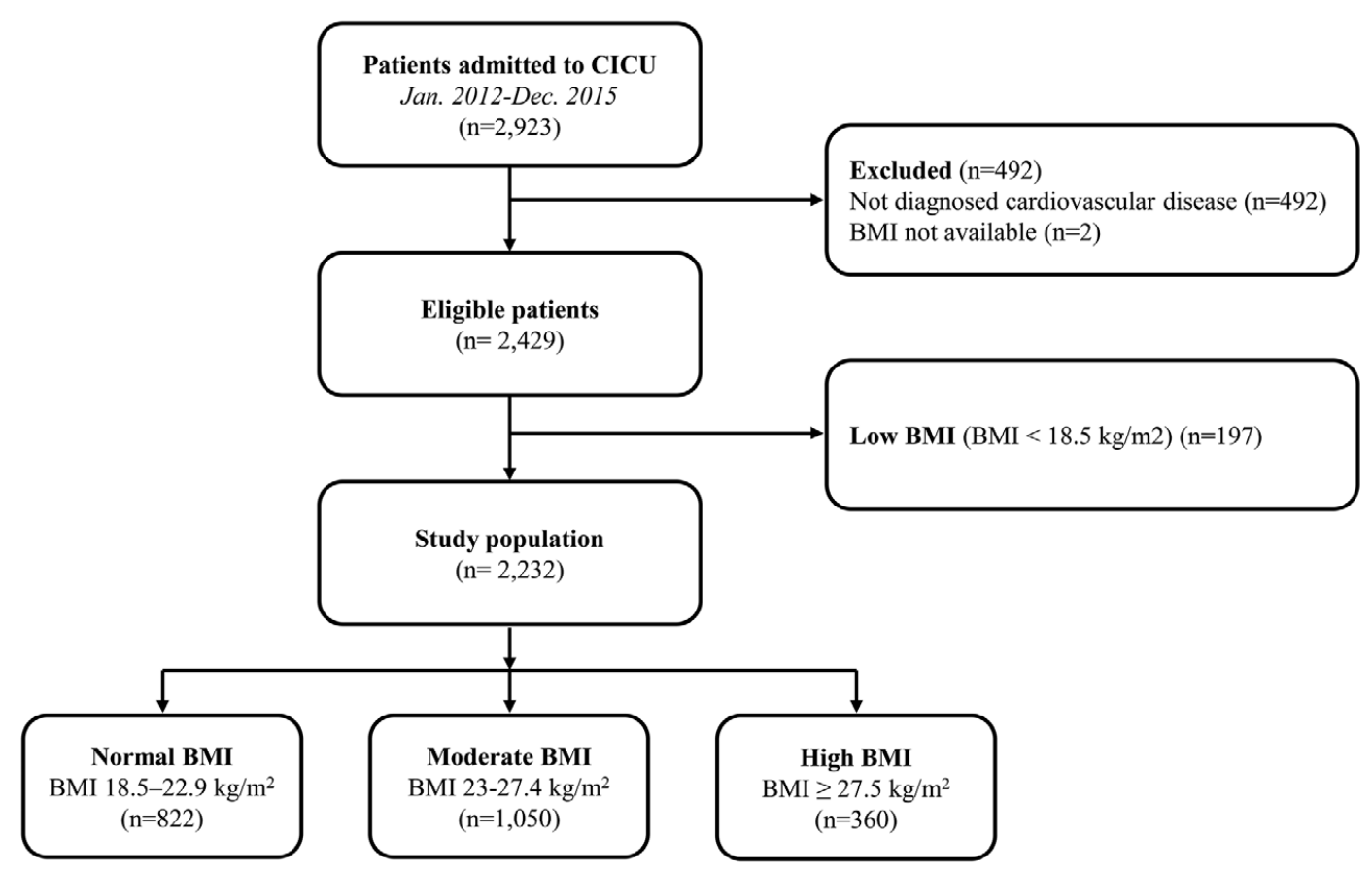

Figure 1. Schematic of patients chosen for the study. BMI, body mass index; CICU, cardiac intensive care unit.

according to BMI cutoff points for Asian populations proposed by World Health Organization expert consultation: patients with BMI calculated at the time of CICU admission $<18.5 \mathrm{~kg} / \mathrm{m}^{2}, 18.5-22.9 \mathrm{~kg} / \mathrm{m}^{2}, 23-27.4 \mathrm{~kg} / \mathrm{m}^{2}$, and $\geq 27.5 \mathrm{~kg} / \mathrm{m}^{2}$ were categorized as low, normal, moderate, and high BMI, respectively (Figure 1). ${ }^{8}$ Low BMI patients were excluded from the analysis to adjust for the possibility of frailty. The Institutional Review Board of Samsung Medical Center approved the study protocol and waived the requirement for informed consent.

\section{Data Collection and Clinical Outcomes}

Clinical, laboratory, and outcome data were collected by a trained study coordinator using a review of hospital records. Patients' weight and height were measured shortly after admission to the CICU, and BMI was calculated (weight in $\mathrm{kg} /$ height in $\mathrm{m}^{2}$ ). Acute Physiology and Chronic Health Evaluation (APACHE) II scores were calculated using data obtained on the 1st day of CICU admission. Treatments during CICU stay, such as use of inotropes or vasopressors, intra-aortic balloon pump, extracorporeal membrane oxygenation, mechanical ventilation, and continuous renal replacement therapy, were also documented.

The primary outcome was 28-day mortality. CICU mortality, in-hospital mortality, and hospital length of stay were also assessed. Deaths were identified through the hospital's electronic medical chart and the Korean national database using a citizen registration number unique to each individual.

\section{Statistical Analysis}

Categorical variables were compared among the 3 BMI groups using the $\chi^{2}$ test and are presented as number and percentage. Comparative analysis of continuous variables was performed using t-test or Mann-Whitney U-test and reported as mean \pm standard deviation or median with interquartile range when applicable. Cox regression analysis was carried out to estimate the hazard ratios (HRs) of the overweight and obese groups and to identify risk factors for prediction of 28-day mortality. Variables with P-value $<0.2$ in the univariable analysis were considered relevant and were included in multiple regression models. The $95 \%$ confidence intervals (CIs) are provided with HRs of each variable where appropriate. All tests were two-sided, and $\mathrm{P}<0.05$ was considered statistically significant. Data were analyzed using R Statistical Software (version 3.2.5; R Foundation for Statistical Computing, Vienna, Austria).

\section{Results}

\section{Baseline Clinical Characteristics}

The baseline characteristics of 2,232 patients according to BMI group are shown in Table 1. Patients in the normal BMI group were older than in the moderate and high BMI groups; the median age of each group was 68, 65, and 61 years, respectively $(\mathrm{P}<0.001)$. The normal BMI group also had higher incidences of chronic kidney disease, liver cirrhosis, malignancy, and acute heart failure as the reason for admission compared with the other groups. Acute coronary syndrome was the primary reason for CICU admission, accounting for $52.6 \%$ of admissions, followed by heart failure at $22.5 \%$. The mean APACHE II score on the 1st day in the CICU in the normal BMI group was 11 (7-17) and was significantly higher than the moderate and high BMI groups, which were 8 (5-15) and 8 (5-14), respectively $(\mathrm{P}<0.001)$. 


\begin{tabular}{|c|c|c|c|c|}
\hline Variables & $\begin{array}{c}\text { Normal BMI } \\
(n=822)\end{array}$ & $\begin{array}{l}\text { Moderate BMI } \\
\quad(n=1,050)\end{array}$ & $\begin{array}{c}\text { High BMI } \\
(\mathrm{n}=360)\end{array}$ & $P$ value \\
\hline Age, years & $68(56-76)$ & $65(55-74)$ & $61(49-71)$ & $<0.001$ \\
\hline Male & $491(59.7)$ & $758(72.2)$ & $244(67.8)$ & $<0.001$ \\
\hline \multicolumn{5}{|l|}{ Comorbidities } \\
\hline Body mass index, $\mathrm{kg} / \mathrm{m}^{2}$ & $21.4(20.4-22.1)$ & $24.8(23.9-26.0)$ & $29.4(28.3-31.2)$ & $<0.001$ \\
\hline Diabetes mellitus & $234(28.5)$ & $332(31.6)$ & $119(33.1)$ & 0.19 \\
\hline Hypertension & $388(47.2)$ & $554(52.8)$ & $207(57.5)$ & 0.003 \\
\hline Cerebrovascular disease & $58(7.1)$ & $53(5.0)$ & $21(5.8)$ & 0.19 \\
\hline Chronic kidney disease & $114(13.9)$ & $104(9.9)$ & $30(8.3)$ & 0.005 \\
\hline Chronic kidney disease without dialysis & $87(76.3)$ & $78(75.0)$ & $25(83.3)$ & \\
\hline Chronic kidney disease with dialysis & $27(23.7)$ & $26(25.0)$ & $5(16.7)$ & \\
\hline Liver cirrhosis & $32(3.9)$ & $21(2.0)$ & $6(1.7)$ & 0.02 \\
\hline Malignancy & $72(8.8)$ & $60(5.7)$ & $13(3.6)$ & 0.002 \\
\hline \multicolumn{5}{|l|}{ Reason for admission } \\
\hline Acute coronary syndrome & $370(45.0)$ & $606(57.7)$ & $199(55.3)$ & $<0.001$ \\
\hline Heart failure & $240(29.2)$ & $193(18.4)$ & $70(19.4)$ & $<0.001$ \\
\hline \multicolumn{5}{|l|}{ Heart failure with reduced ejection fraction } \\
\hline Ischemic cardiomyopathy & $63(35.6)$ & $57(41.9)$ & $20(40.0)$ & \\
\hline Dilated cardiomyopathy & $65(36.7)$ & $45(33.1)$ & $16(32.0)$ & \\
\hline Valvular heart disease ${ }^{a}$ & $25(14.1)$ & $20(14.7)$ & $9(18.0)$ & \\
\hline Myocarditis with or without pericarditis & $13(7.3)$ & $17(12.5)$ & $5(10.0)$ & \\
\hline Stress-induced cardiomyopathy ${ }^{b}$ & $12(6.8)$ & $13(9.6)$ & $7(14.0)$ & \\
\hline Hypertrophic or restrictive cardiomyopathy & $12(6.8)$ & $6(4.4)$ & $2(4.0)$ & \\
\hline Heart failure with preserved ejection fraction & $50(28.2)$ & $35(25.7)$ & $11(22.0)$ & \\
\hline Arrhythmia & $118(14.4)$ & $134(12.8)$ & $41(11.4)$ & 0.339 \\
\hline Acute aortic syndrome, type B & $49(6.0)$ & $65(6.2)$ & $26(7.2)$ & 0.705 \\
\hline Pericardial disease & $16(1.9)$ & $21(2.0)$ & $8(2.2)$ & 0.952 \\
\hline Pulmonary thromboembolism & $14(1.7)$ & $21(2.0)$ & $14(3.9)$ & 0.052 \\
\hline Infective endocarditis & $15(1.8)$ & $10(1.0)$ & $2(0.6)$ & 0.107 \\
\hline Post-cardiac arrest & $47(5.7)$ & $68(6.5)$ & $25(6.9)$ & 0.68 \\
\hline APACHE II score & $11(7-17)$ & $8(5-15)$ & $8(5-14)$ & $<0.001$ \\
\hline
\end{tabular}

Values are median with interquartile range or $\mathrm{n}(\%)$. aValvular heart disease includes congenital heart disease. ${ }^{\mathrm{b}}$ Stress-induced cardiomyopathy includes tachycardia-induced cardiomyopathy and peripartum cardiomyopathy. APACHE II, Acute Physiology and Chronic Health Evaluation II; CICU, cardiac intensive care unit.

\section{In-Hospital Management and Clinical Outcomes}

The normal BMI group most frequently required inotropes or vasopressors $(34.5 \%$ vs. $23.3 \%$ vs. $25.6 \%, \mathrm{P}<0.001)$ (Table 2). There was no significant difference among the 3 BMI groups in the frequency of use of organ support devices, such as intra-aortic balloon pump, extracorporeal membrane oxygenation, mechanical ventilator, and continuous renal replacement therapy. Patients were followed for a median of 650 days $(227-1,104)$ or until death. A total of $124(5.6 \%)$ patients died during the 28-day follow-up. The 28-day mortality rates according to BMI were $7.1 \%$, $4.5 \%$, and $5.3 \%$ in the normal, moderate and high BMI groups, respectively $(\mathrm{P}=0.052)$. In-hospital death was also lower in the moderate and high BMI groups than in the normal BMI group, but the difference was not statistically significant $(8.5 \%$ vs. $5.8 \%$ vs. $5.8 \%, \mathrm{P}=0.051)$. Cox regression analysis revealed that the unadjusted HR of moderate and high BMI groups for 28-day mortality was $0.62(95 \%$ CI, 0.41-0.94; $\mathrm{P}=0.024)$ and $0.80(95 \% \mathrm{CI}, 0.47-1.38$; $\mathrm{P}=0.429)$, respectively, and the adjusted $\mathrm{HR}$ was $0.80(95 \%$ CI, 0.52-1.21; $\mathrm{P}=0.291)$ and $0.95(95 \% \mathrm{CI}, 0.55-1.65$; $\mathrm{P}=0.861$ ) (Table 3). After multivariable adjustment, APACHE II scores, liver cirrhosis, malignancy, history of post-cardiac arrest, use of vasoactive drugs, mechanical ventilation, and continuous renal replacement therapy were independent predictors of 28-day mortality (Table 3). We also performed multivariable analysis using the logistic regression method for sensitivity analysis (Supplementary Table 1) and the results were similar with Cox regression analysis. The median hospital length of stay was 7, 5, and 5 days in the normal, moderate and high BMI groups, respectively $(\mathrm{P}<0.001)$.

In the subgroup of patients with acute heart failure, 28 -day ( $10.8 \%$ vs. $10.4 \%$ vs. $8.6 \%, \mathrm{P}=0.86)$, CICU $(9.2 \%$ vs. $9.8 \%$ vs. $10.0 \%, \mathrm{P}=096)$, and hospital $(113.3 \%$ vs. $14.0 \%$ vs. $11.4 \%, \mathrm{P}=0.86$ ) mortality were not different among the 3 groups (Figure 2). Also, multivariable analysis demonstrated that the moderate and high BMI groups were not associated with 28-day mortality in any of the subgroups (Supplementary Table 2). There was no difference in 28-day ( $5.7 \%$ vs. $3.3 \%$ vs. $5.0, \mathrm{P}=0.18)$, CICU $(4.3 \% \%$ vs. $3.5 \%$ vs. $4.0 \%, \mathrm{P}=0.79)$, and hospital $(7.0 \%$ vs. $3.8 \%$ vs. $5.0 \%$, $\mathrm{P}=0.08$ ) mortality according to $\mathrm{BMI}$ in patients with acute coronary syndrome. 
Table 2. In-Hospital Management and Clinical Outcomes of Patients Admitted to CICU

\begin{tabular}{|c|c|c|c|c|}
\hline Variables & $\begin{array}{c}\text { Normal BMI } \\
(\mathrm{n}=\mathbf{8 2 2})\end{array}$ & $\begin{array}{l}\text { Moderate BMI } \\
(n=1,050)\end{array}$ & $\begin{array}{l}\text { High BMI } \\
(\mathrm{n}=360)\end{array}$ & $P$ value \\
\hline \multicolumn{5}{|l|}{ In-hospital managements } \\
\hline Inotropes or vasopressors & $284(34.5)$ & $245(23.3)$ & $92(25.6)$ & $<0.001$ \\
\hline Intra-aortic balloon pump & $46(5.6)$ & $40(3.8)$ & $12(3.3)$ & 0.10 \\
\hline Extracorporeal membrane oxygenation & $40(4.9)$ & $64(6.1)$ & $24(6.7)$ & 0.37 \\
\hline Mechanical ventilation & $153(18.6)$ & $153(14.6)$ & $61(16.9)$ & 0.06 \\
\hline Continuous renal replacement therapy & $81(9.9)$ & $77(7.3)$ & $27(7.5)$ & 0.12 \\
\hline \multicolumn{5}{|l|}{ Clinical outcomes } \\
\hline \multicolumn{5}{|l|}{ Mortality } \\
\hline $\mathrm{CICU}$ & $48(5.8)$ & $47(4.5)$ & $17(4.7)$ & 0.39 \\
\hline Cardiac death & $30(3.6)$ & $36(3.4)$ & $15(4.2)$ & 0.811 \\
\hline Non-cardiac death & $18(2.2)$ & $11(1.0)$ & $2(0.6)$ & 0.037 \\
\hline Hospital & $70(8.5)$ & $61(5.8)$ & $21(5.8)$ & 0.05 \\
\hline Cardiac death & $42(5.1)$ & $43(4.1)$ & $18(5.0)$ & 0.543 \\
\hline Non-cardiac death & $28(3.4)$ & $18(1.7)$ & $3(0.8)$ & 0.007 \\
\hline 28-day & $58(7.1)$ & $47(4.5)$ & $19(5.3)$ & 0.052 \\
\hline Cardiac death & $39(4.7)$ & $36(3.4)$ & $17(4.7)$ & 0.299 \\
\hline Non-cardiac death & $19(2.3)$ & $11(1.0)$ & $2(0.6)$ & 0.023 \\
\hline \multicolumn{5}{|l|}{ Length of stay } \\
\hline CICU & $2(1-4)$ & $2(1-3)$ & $2(1-3)$ & $<0.001$ \\
\hline Hospital & $7(4-15)$ & $5(3-10)$ & $5(3-10)$ & $<0.001$ \\
\hline
\end{tabular}

Values are median with interquartile range or $\mathrm{n}(\%)$. CICU, cardiac intensive care unit.

\begin{tabular}{|c|c|c|c|c|c|c|}
\hline & \multicolumn{3}{|c|}{ Univariable } & \multicolumn{3}{|c|}{ Multivariable } \\
\hline & HR & $95 \% \mathrm{Cl}$ & $P$ value & Adjusted HR & $95 \% \mathrm{Cl}$ & $P$ value \\
\hline Body mass index ${ }^{a}$ & - & - & - & - & - & - \\
\hline Moderate (BMI 23-27.4kg/m²) & 0.62 & $0.41-0.94$ & 0.024 & 0.80 & $0.52-1.21$ & 0.291 \\
\hline High $\left(\mathrm{BMI} \geq 27.5 \mathrm{~kg} / \mathrm{m}^{2}\right)$ & 0.80 & $0.47-1.38$ & 0.429 & 0.95 & $0.55-1.65$ & 0.861 \\
\hline Age $\geq 65$ years & 1.49 & $1.01-2.19$ & 0.044 & 1.16 & $0.77-1.75$ & 0.481 \\
\hline APACHE II score & 1.16 & $1.13-1.18$ & $<0.001$ & 1.04 & $1.01-1.07$ & 0.020 \\
\hline Liver cirrhosis & 4.23 & $2.27-7.89$ & $<0.001$ & 1.91 & $0.99-3.68$ & 0.055 \\
\hline Malignancy & 2.25 & $1.31-3.89$ & 0.003 & 1.73 & $0.99-3.01$ & 0.055 \\
\hline Main reason for admission ${ }^{b}$ & - & - & - & - & - & - \\
\hline Acute heart failure & 2.79 & $1.85-4.21$ & $<0.001$ & 1.54 & $1.00-2.37$ & 0.050 \\
\hline Other & 0.90 & $0.52-1.56$ & 0.702 & 0.88 & $0.50-1.55$ & 0.663 \\
\hline Post-cardiac arrest & 8.40 & $5.60-12.59$ & $<0.001$ & 1.85 & $1.17-2.94$ & 0.009 \\
\hline Vasoactive drugs & 24.85 & $13.33-46.32$ & $<0.001$ & 6.48 & $3.22-13.03$ & $<0.001$ \\
\hline Mechanical ventilation & 13.27 & $8.82-19.95$ & $<0.001$ & 2.04 & $1.22-3.42$ & 0.007 \\
\hline Continuous renal replacement therapy & 17.05 & $11.69-24.87$ & $<0.001$ & 2.74 & $1.73-4.36$ & $<0.001$ \\
\hline
\end{tabular}

aReference group is normal BMI $\left(18.5-22.9 \mathrm{~kg} / \mathrm{m}^{2}\right)$. ${ }^{\mathrm{b}}$ Reference group is all other cardiovascular diseases except heart failure. APACHE, Acute Physiology and Chronic Health Evaluation; Cl, confidence interval; HR, hazard ratio.

\section{Discussion}

We investigated whether the obesity paradox exists in patients with cardiovascular disease requiring cardiac intensive care. The major findings of this study were: (1) the moderate and high BMI groups were relatively younger and had lower severity scores than the normal BMI group; (2) the 28-day mortality was not significantly different among the normal, moderate and high BMI groups. Furthermore, both moderate and high BMI were not prognostic predictors for 28-day mortality after adjusting for relevant factors; (3) Acute Physiology and Chronic Health Evalua- tion II scores, liver cirrhosis, malignancy, history of cardiac arrest, and need for organ support treatment were independent predictors of 28-day mortality.

In general, obese patients may be at a disadvantage in critical care because of procedural difficulties related to anatomy or altered drug doses in plasma resulting from changes in pharmacokinetics. However, as shown in patients with chronic illnesses such as chronic obstructive pulmonary disease, endstage renal disease, and chronic heart failure, ${ }^{9-11}$ several studies of patients in medical and surgical ICUs have suggested the existence of an obesity paradox in critically ill patients by demonstrating the 


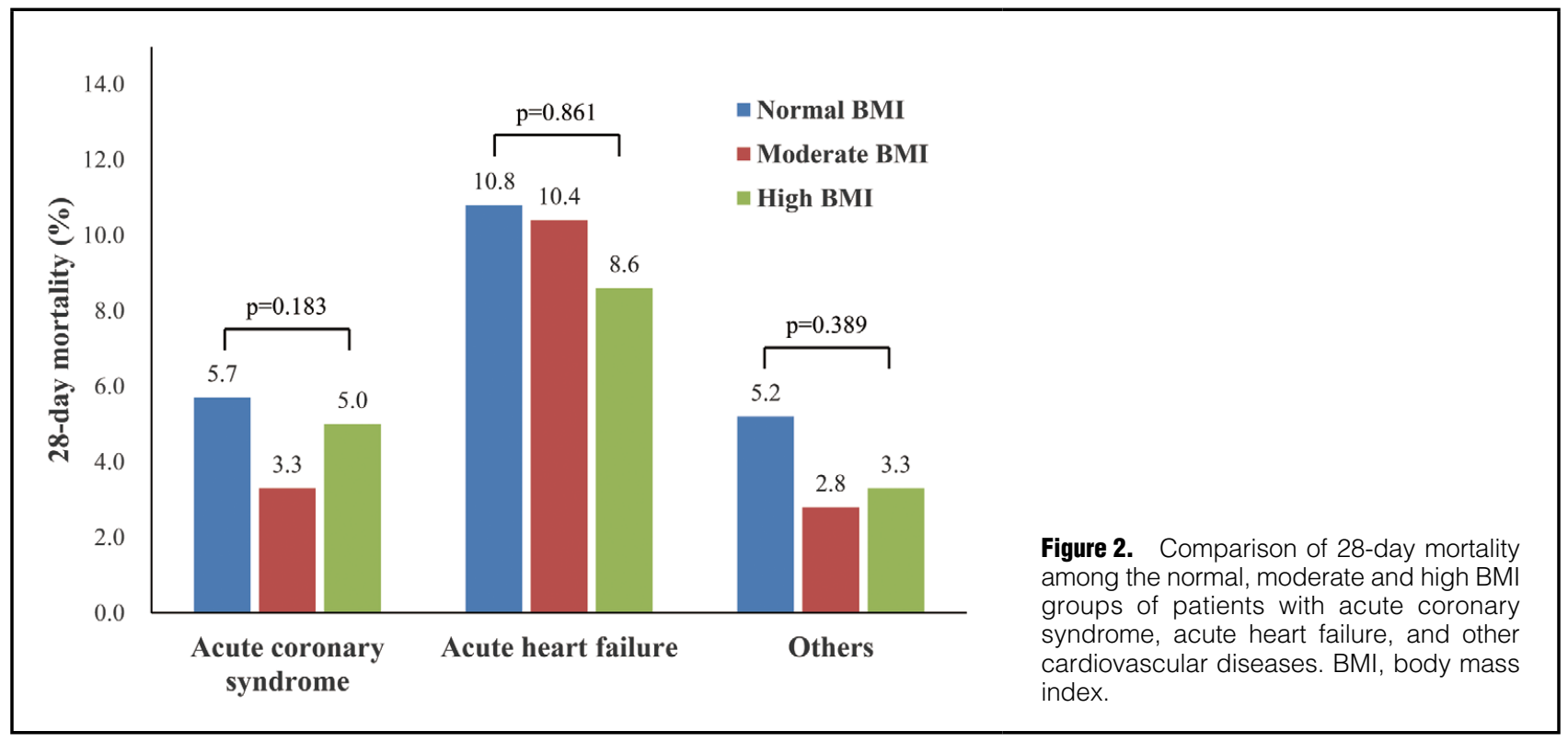

association between overweight or obese patients and improved short-term mortality rates..$^{5,12-15}$

There are some differences between our findings and results of previous studies (Supplementary Table 3). In this study, we only included non-surgical patients with cardiovascular disease, but previous studies included either only surgical patients or both medical and surgical patients. Furthermore, admission type was an independent factor associated with death in one study. ${ }^{13}$ Although direct comparison of severity of illness among patients included in each study is difficult because each study used different scoring systems, both the proportion of patients receiving organ support and mortality rates were much lower in our study than in previous studies. We consider that the differences in patient characteristics, interventions, and mortality are partly related to the obesity paradox, but further studies are needed to prove our assumption. Previous studies have suggested several theories for the obesity paradox in critically ill patients admitted to the ICU. One is that obese patients have a nutritional reserve that helps to overcome the severe catabolic state associated with critical illness. Stapleton et al demonstrated an altered inflammatory response with lower level pro-inflammatory cytokines in patients who were obese and had acute lung injury, the opposite to people who were healthy and obese. This might be related to the obesity paradox, although the mechanism is unclear. ${ }^{16,17}$

Abdulla and colleagues performed a pooled analysis of 5 registries that included high-risk patients with myocardial infarction or chronic heart failure who had mortality rates greater than $50 \%$ and also did not show evidence of any protective effect of obesity. ${ }^{18}$ Conversely, a recent study in Japan showed better prognosis of overweight patients compared with normal and underweight patients who had severely decompensated acute heart failure and were admitted to ICU. ${ }^{19}$ Similar to other areas of critical illness, the presence of the obesity paradox in cardiac critical care remains contradictory. In previous studies, the overweight or obesity group was often relatively younger and had lower severity scores compared with the normal weight group, which may affect clinical outcomes. Recently published research has shown that the trend in observed unadjusted mortality in different obesity classes is similar to that of illness severity. ${ }^{20}$ In the present study, we identified that specific underlying diseases and organ support treatments were related to 28-day morality, rather than BMI or diagnosis at admission. Overt organ dysfunction or failure to overwhelm the protective effect of obesity is based on nutritional support and anti-inflammatory cytokines in patients requiring acute cardiac critical care regardless of diagnosis.

\section{Study Limitations}

First, because this study was conducted as a retrospective cohort study, there is a potential risk of confounding and bias. Second, a heterogeneous group of patients requiring acute cardiac critical care was included, rather than selecting patients with specific cardiovascular diseases. Therefore, the APACHE II score was used as a severity scoring system in all included patients. Although the APACHE II score has been validated in ICU patients with various cardiovascular diseases, ${ }^{21}$ it remains to be determined whether it adequately reflects severity. Third, BMI is calculated with only height and weight and does not accurately reflect body composition. Therefore, BMI could be overestimated in the setting of volume overload in patients with acute decompensated heart failure. Novel methods that address these concerns are needed to more accurately elucidate the effect of BMI.

\section{Conclusions}

Obesity may be not associated with survival benefit in patients requiring acute cardiac critical care, particularly after adjusting for the relatively young age and low APACHE II score of the obese patients.

\section{Acknowledgments}

All authors contributed extensively to the work presented here. S.J.N. and J.H.Y. had full access to all of the data reported and take respon- 
sibility for both its integrity and the accuracy of its analysis. S.J.N., J.H.Y., C.R.C., K.J., and G.Y.S. contributed to study conception and design. S.J.N., J.H.Y., J.M.L., Y.B.S., J.O.C., J.Y.H., J.H.C., S.H.C., and H.C.G. contributed to acquisition of data; S.J.N., J.H.Y., J.H.A. and K.C.C. contributed to analysis and interpretation of data; S.J.N. and J.H.Y. drafted the manuscript; all authors participated in critical revision and approved the final version of the manuscript.

\section{Funding / Competing Interests}

None declared.

\section{Provenance and Peer Review}

Not commissioned; externally peer reviewed.

Disclosures / Competing Interests / Grant Support

None.

\section{References}

1. Haslam DW, James WP. Obesity. Lancet 2005; 366: 1197-1209.

2. Roger VL, Go AS, Lloyd-Jones DM, Benjamin EJ, Berry JD, Borden WB, et al. Heart disease and stroke statistics - 2012 update: A report from the American Heart Association. Circulation 2012; 125: e2-e220.

3. Calle EE, Thun MJ, Petrelli JM, Rodriguez C, Heath CW Jr. Body-mass index and mortality in a prospective cohort of U.S. adults. $N$ Engl J Med 1999; 341: 1097-1105.

4. Ni YN, Luo J, Yu H, Wang YW, Hu YH, Liu D, et al. Can body mass index predict clinical outcomes for patients with acute lung injury/acute respiratory distress syndrome?: A meta-analysis. Crit Care 2017; 21: 36.

5. Pickkers P, de Keizer N, Dusseljee J, Weerheijm D, van der Hoeven JG, Peek N. Body mass index is associated with hospital mortality in critically ill patients: An observational cohort study. Crit Care Med 2013; 41: 1878-1883.

6. Bucholz EM, Rathore SS, Reid KJ, Jones PG, Chan PS, Rich MW, et al. Body mass index and mortality in acute myocardial infarction patients. Am J Med 2012; 125: 796-803.

7. Shah R, Gayat E, Januzzi JL Jr, Sato N, Cohen-Solal A, diSomma $\mathrm{S}$, et al. Body mass index and mortality in acutely decompensated heart failure across the world: A global obesity paradox. J Am Coll Cardiol 2014; 63: 778-785.

8. WHO Expert Consultation. Appropriate body-mass index for Asian populations and its implications for policy and intervention strategies. Lancet 2004; 363: 157-163.

9. Landbo C, Prescott E, Lange P, Vestbo J, Almdal TP. Prognostic value of nutritional status in chronic obstructive pulmonary disease. Am J Respir Crit Care Med 1999; 160: 1856-1861.

10. Kalantar-Zadeh K, Streja E, Kovesdy CP, Oreopoulos A, Noori
$\mathrm{N}$, Jing J, et al. The obesity paradox and mortality associated with surrogates of body size and muscle mass in patients receiving hemodialysis. Mayo Clin Proc 2010; 85: 991-1001.

11. Sharma A, Lavie CJ, Borer JS, Vallakati A, Goel S, LopezJimenez F, et al. Meta-analysis of the relation of body mass index to all-cause and cardiovascular mortality and hospitalization in patients with chronic heart failure. Am J Cardiol 2015; 115: $1428-1434$

12. Utzolino S, Ditzel CM, Baier PK, Hopt UT, Kaffarnik MF. The obesity paradox in surgical intensive care patients with peritonitis. $J$ Crit Care 2014; 29: 887.e881-e885.

13. Sasabuchi Y, Yasunaga H, Matsui H, Lefor AT, Horiguchi H, Fushimi K, et al. The dose-response relationship between body mass index and mortality in subjects admitted to the ICU with and without mechanical ventilation. Respir Care 2015; 60: $983-$ 991.

14. Arabi YM, Dara SI, Tamim HM, Rishu AH, Bouchama A, Khedr MK, et al. Clinical characteristics, sepsis interventions and outcomes in the obese patients with septic shock: An international multicenter cohort study. Crit Care 2013; 17: R72.

15. Lim SY, Choi WI, Jeon K, Guallar E, Koh Y, Lim CM, et al. Body mass index and mortality in Korean intensive care units: A prospective multicenter cohort study. PLoS One 2014; 9: e90039.

16. Stapleton RD, Dixon AE, Parsons PE, Ware LB, Suratt BT; NHLBI Acute Respiratory Distress Syndrome Network. The association between BMI and plasma cytokine levels in patients with acute lung injury. Chest 2010; 138: 568-577.

17. Steinberg GR. Inflammation in obesity is the common link between defects in fatty acid metabolism and insulin resistance. Cell Cycle 2007; 6: 888-894.

18. Abdulla J, Kober L, Abildstrom SZ, Christensen E, James WP, Torp-Pedersen C. Impact of obesity as a mortality predictor in high-risk patients with myocardial infarction or chronic heart failure: A pooled analysis of five registries. Eur Heart J 2008; 29: 594-601.

19. Matsushita M, Shirakabe A, Hata N, Shinada T, Kobayashi N, Tomita K, et al. Association between the body mass index and the clinical findings in patients with acute heart failure: Evaluation of the obesity paradox in patients with severely decompensated acute heart failure. Heart Vessels 2017; 32: 600-608.

20. Ball L, Serpa Neto A, Pelosi P. Obesity and survival in critically ill patients with acute respiratory distress syndrome: A paradox within the paradox. Crit Care 2017; 21: 114.

21. Knaus WA, Draper EA, Wagner DP, Zimmerman JE. APACHE II: A severity of disease classification system. Crit Care Med 1985; 13: 818-829.

\section{Supplementary Files}

Please find supplementary file(s);

http://dx.doi.org/10.1253/circj.CJ-18-0873 